\title{
Alternative Food Networks Development and Multiple Actors' Participation in China: A Review
}

\author{
Huan Yang \\ Institute for China Rural Studies, Central China Normal University, China \\ 152 Luoyu Rd, Hongshan Qu, Wuhan Shi, Hubei Sheng 430072, China. \\ Tel: +86-27-67865845 Fax: +86-27-67865189.E-mail: yanghuan11180@,163.com
}

(Received: Jul 3, 2015; Reviewed: May 10, 2016; Accepted: Aug 10, 2016)

\begin{abstract}
This article reviews the studies about the alternative food network development in China, summarizes the results and identifies the issues for further research. It first introduces different theoretical perspectives in alternative food network studies in China, including community supported agriculture, nested market, short food supply chains and producerconsumer connection. The causes of rising alternative food networks are the serious food safety problem, the un-balanced power between different actors in the mainstream agrofood system and the increasing number of middle income citizens. Its development close relates to the changes in the international agro-food system. And the government dominates the establishment of the certification system and give limited support to the emerging food networks. The consumers and majority of producers are social elites, and the small scale farmers participate in the networks under the support of intermediaries. Further studies can pay more attention to following issues: the landscape of alternative food networks development in China, the value construction processes between different actors, the role of companies in alternative food network construction and introducing technical perspective of ecological agriculture into research.
\end{abstract}

Keywords: Alternative food networks, multiple stakeholder participation, community supported agriculture, nested market, short food supply chain, producer-consumer connection

\section{Introduction}

Since the 1950s, the global agro-food system has experienced significant changes, including the increasing dependence on petroleum energy, chemical fertilizer and pesticide, marketing dominating the food production, the squeezing of producers' profit by the up and downstream of the food chains and the globalization of food and agriproducts market (World Bank, 2006; Busch and Bain, 2004). These changes lead to a series of ecological and social problems, such as the degradation of ecological environment, un-sustainable using of natural resources, the marginalizing of small producers, the food safety problems and the healthy problem caused by over-processed food products (Ye, 2015; Goodman et al., 2012). In the 1960s, social movements relating to alternative food networks emerged, aiming to solve these problems by establishing new food production, trading and consuming structure, re-connecting consumers and producers. The practices of alternative food networks are diverse, including community-supported agriculture (CSA), farmers' market, nested market and buying clubs (Si et al., 2015)

The alternative food networks first emerged in Japan, Switzerland and Germany, and expanded to Europe and US rapidly. 
It becomes the hot topic in development research and also the focus of "sannong" (farmer, rural area and agriculture) in China. Comparing to developed countries, China is facing serious pressure in sustainable development of agriculture and food system because of the big population, lower per capital share of resources and degradation of nature resources. At the same time, the over use of chemical fertilizer and pesticide in agriculture production, additives in food processing bring enormous food safety problems and negative social and economic impacts (Ye, 2015; Wen, 2007). Dealing with this, on one hand, consumers and producers spontaneously initiated ecological food production and consuming model, like the Farmers 'Friend restaurant and market. On the other hand, external actors, like researchers and NGOs also initiative a series of practices under the idea of alternative food networks, including the "ecological farming" project in southwest China supported by Partnerships for Community Development (PCD, a NGO in Hongkong) the "community-supported agriculture model" introduced by School of Agricultural Economics and Rural Development, Renmin University of China, the "nested market" practice promoted by College of Humanity and Development, China Agriculture University. These practices attracted a lot attentions in the society and promoted the development of alternative food networks all over China.

In recent years, researchers have done many researches of alternative food networks in China, covering the introducing of the concepts, the social and economic background, the development processes and the outcomes (Qu and Jiao, 2013; Fu and Ye, 2015). Researchers from different disciplines used different concepts to explore the functions, practices and development of the AFNs, and form an open platform for this theme. By overview the literatures, this article will analyze the concepts used, retrospect the AFN development in China and especially the different actors participation and interactions in the processes. We aim to provide an overall picture for the readers and explore the focuses for further research.

\section{Different Conceptual Perspectives of AFN Research in China}

A lot of researchers have paid attention to AFN, but no precise definition has been given to it. Feenstra (Feenstra, 1997) characterized AFN as "rooted in particular places, aim to be economically viable for farmers and consumers, use ecologically sound production and distribution practices, and enhance social equity and democracy for all members of the community." Its alternativeness is reflected in the shortened distance between consumers and producers, the improved communication and trust between the two parties, introduced idea of fair trade and community development (Watts et al., 2005; Lu, 2016). This concept includes diverse emerging social practices and overlaps with several concepts, like short food supply chain (Marsden et al., 2000), nested market (van der Ploeg et al., 2012) and community-supported agriculture (Shi, 2015). Some researchers introduced these concepts into China, and some researchers suggest local concept from grassroots 
practices, like "direct link of farmer and consumer" (Xu and Zhou, 2016). These concepts research the similar phenomenon in practice but with different emphasis.

\subsection{Community-supported Agriculture (CSA)}

CSA is an important model of AFN and has the most influence in China in both practice and research. In the literature, Shen (2006) and $\mathrm{He}(\mathrm{He}, 2007)$ are the early ones who introduced the CSA concept into China. They described the development of CSA in Western countries, its daily operations and characteristics, and considered this model as an approach to support the local agricultural development, protect the local food supply, provide safe food to consumers and opportunity to small scale farms, reduce agriculture's negative impact on environment.

In China, the recognized earliest CSA practice is the "Little Donkey Farm", which was established by the School of Agricultural Economics and Rural Development, RUC and Haidian District Government of Beijing as an base of production, education and research. From Jan. 2010, the China CSA conference was held annually by the Rural Construction Center, RUC and the Little Donkey Farm. The conference has organized 7 times and attracted people from practice, research and government agencies. Not only the series of projects and activities promote the CSA model all over the country, also the Little Donkey Farm becomes an important case in CSA research (Chen, 2013a; Shi et al., 2011a; Chen, 2015; Cheng et al., 2011). The authors think that the farm has spontaneously adopted an action research paradigm for the CSA model. Based on the progresses in practices, a lot of studies have been down within this field. More than 150 article are found with the key word "community supported agriculture" in CNKI.

Literally, community is the group of people who live within a common area and form same social identity and value in daily interactions (Xiao, 2011). Pan and Du (Pan and Du, 2012) note that emphasizing "community" in the CSA model is because the significant functions of $A F N$ in reconstruction of micro social structure. On one hand, it helps to organize entity with operational functions, like consumer groups, the producer organizations; on the other hand, it represents symbolic groups, enabling people to explore a possible approach for less energy consumption and food pollution in food supply chains through collective actions. Hence, in School of Agricultural Economics and Rural Development's practice and research, CSA is important part of rural construction and community development. It breaks through the mainstream in rural development, which aims for modernization and industrialization, by promoting ecological, economic and social sustainability through ecological agriculture and fair trade between rural and urban (Si and Scott, 2015). Other researchers also pay a lot of attention to the formulation of consumer communities and their functioning (Zeng et al., 2014; Shuai, 2013).

\subsection{Nested Market}

"Nested market" was first proposed by College of Humanity and Development, 
China Agricultural University in the project "Reducing Poverty through Nested Market". Based on the rich experiences in development field, the project adopted action research approach from the beginning, cooperating with four villages in Yi County Hebei Province and Yanqing County in Beijing. It promoted the direct food transition and trust building between farmers and consumers, increased the farmers' income and recovered the rural environment and traditional production. The nested market is the institutionalized market relations as well as materialized trading places. It is the trade happened between particular consumers and producers with particular products through particular carring system. The special products include high quality products, local products, organic food, rural turism; particular consumers are the ones who can distinguish these spcial products and services; the particular carrying systems refer to the farmers' market, farm shop and delivering scheme (Ye and Wang, 2011).

Van der Ploeg (van der Ploeg et al., 2012) indicates that the word "nested" emphasises the special realtions between the emerging market and the social structures it embeded in. Different from the mainstream food system which attemps to re-constructe the structure it embededin, nested market explicitely recognized its embededness. First, the nested market aims to embed into the existing social structure and solve the problems in the mainstream of food system by promoting the trust between consumers and producers. Second, the nested marketed embed in the local resource structure, respecting and recognizing the local resources endowment, like climate, production structure and labour investment. Third, the nested market values the multi-function of agriculture, not only the economic functions like impoving the producers' income, improving consumers' choices, but also the social functions of promoting social trust and the ecological functions of maintaining the rural natural and social landscape (Ye et al., 2012).

Nested market perspective also identifies AFN's functioning mechanism as common pool resource. The concept "common pool resource" borrows from Ostrom. Under the nested market perspective, common pool resources not only refer to particular resources and products for trading, also include the shared rules and expectations to products between consumers and producers relating to the products' "specialty" (Ye et al., 2012). This concept shows the space for all the participants to excise their agencies to construct the emerging market. The consumers, producers, intermediaries (including research institutes, NGO, social enterprise) can participate in the quality standard setting based on their own needs and values. The common recognized values and rules are formed in the interactions, not decided by single actor. And the final products are the materialized common rules.

\subsection{Short food supply chain}

Short food supply chain (SFSC) is also a common used concept in AFN studies, originated from food supply chain research in food system studies (Marsden et al., 2000). Du and Tan are the early 
researchers who introduced this concept into China. They suggest that the word "short" has several levels of meanings. The first is the shorted space distance, which implies the localization of food consumption and helps to reduce the cost and environment pollution in food transportation. The second is the direct linkage between consumers and producers (Tan and Du, 2010b; Zhao and Ge, 2014). The third is the transparency and visibility of information which means that consumers can get adequate information about food production and transition (Yin and Zhu, 2016).

$\mathrm{Du}$ and Tan indicate that the food supply chain development in China is at the stage of modernization and the level of food processing is lower and length of food supply chain is much lower than the western countries. But the lack of effective monitor of the food industry leads to the serious negative effects ( $\mathrm{Du}$ and Tan, 2009). The mainstream of ecologcial agriculture in China is still improving and developing the modern agriculture, not going to the alternative agriculture model of the post-modern stage. The authors call it "constructive" modern agriculture, which takes the ecogical functions and food safety seriously, but does not pay much attention to non-economic values like energy saving, emission reduction and localized consumption. At the samet time, it still persuits the large scale in production. As the number of AFN practicesincreasing, the authors recognize the advantages of SFSC farms in environment protection, food safety, fair distributiono f benefits. But they piont out that its economic sustainability is far from clear, and the SFSC's referential significance is the seeking and cultivating the farm operators with ecological agriculture idea and technical skills (Tan and Du, 2015).

\subsection{Direct link of farmer and consumer}

"Direct link of farmer and consumer" is a local concept proposed by Zhou and his team in School of Agricultural Economics and Rural Development, RUC to analyze the phenomenon of the emerging alternative agriculture model. They note that "the ultimate goal of direct link of farmer and consumer is establishing the human relations and consolidate the mutual trust between producers and consumers" (Xu and Zhou, 2016). The authors indicate that as the commercialization and marketization of land and labor, the profit pursuit of capital fosters the enterprises' opportunistic practices, and further leading to the worsening of food safety problems. Based on the individual rationality, producers and consumers adopt "individual self-protection action". The producers use different producing practices to the food consumed by themselves and sold to the market. This ensures safety in their own consumption while keeping the profit in agriproducts marketing. The consumers reduce the expense and cost of mainstream food consumption, and search for the alternative food channels (Xu and Zhou, 2014). At the same time, the authors note the possibility of "individual self-protection" changing to "collective protection" for the increasing scale of producers' and consumers' selfprotection actions. The precondition is the promoting the cooperation between farmers and urban consumers, enhancing their mutual 
understanding and trust (Xu et al., 2013).

Under the concept "direct link of farmer and consumer", Zhou and his team analyze the characteristics of producers and consumers in China and their challenges to the AFN development. At the producer side, dispersive small farmers are not capable to develop market because the quantity, quality and price standards of their products are different to fit the competition in the market. Therefore, the assistance of intermediaries, like farm market, urban farm, NGO, is important in linking farmers to market (Xu and Zhou, 2014). This consistent with our findings in cooperative studies that farmer cooperatives play important roles to bring scatted farmers into high quality food market (Yang et al., forthcoming). At the consumer side, the lack of consumer responsibility consciousness is an un-responsible behavior. It mainly reflects in the consumption standard - "good products with low price", and the lack of consumption cooperation ( $\mathrm{Xu}$ and Zhou, 2016). So the establishment of "collective protection" in food safety system needs the participation of all actors in the system to reconstruct the cracked social relations.

\section{Alternative Food Networks develop- ment in China}

\subsection{The Social Background of Alternative Food Networks development}

The emerging and development of AFN in China closely links to the contemporary social economic background. Food safety problem is the immediate cause of emerging of community-supported agriculture. After the reform, consumers' pursue of food consumption changes from quantity to quality as the improving of living standard. But the frequent food safety events, like melamine milk scandal, magdala red egg event, poison Chinese Chive in Shenyang, captured high public attention in food safety issue, evening cause certain social panic (Du et al., 2012). In order to protect their heath, some consumers initiated the communitysupported agriculture by themselves and estalished long-term relations with the ecological producing farmers, like the Green League of Mothers' Living Center (Wu and Liu, 2014). The primary motivation for the consumers joining CSA is to access to high quality safe food (Chen et al., 2011).

The unbalance power between different actors in food system is the internal motive for the AFN development in China. In the modern food system, the large retailers and input suppliers take the pricing power while producers and consumers become the price taker (Wu and Liu, 2014). This causes a series of problems. Firstly, the food safety becomes the victim of low price. In the production side, the farmers adapt to the squeezing of profit by using a lot of chemical fertilizer, pesticide and additives to raising the yield, improving the product appearance. The processors use poor quality raw materials and large quantity of additives to achieving "good quality with low price" (Ye, 2015). The consumers cannot judge the quality of food from the appearance and turn to choose "good quality with low price" products. Although this seems the result of rational choices of different actors, it brings serious food safety problem and pushes the producers and consumers looking for the alternative 
organizing model of food system. Secondly, the sustainability of rural community is in risk. On one hand, agriculture becomes the main source of pollution and threaten the ecological environment protection; on the other side, the low profit leads to the out flow of young and middle-aged labor to cities and threaten the social sustainability of the villages. In the new Rural Construction Movement, AFN is treated as the approach to escape the market control and re-built the trust and cooperation between consumers and producers, further enhancing the good interaction between urban and rural (Pan and $\mathrm{Du}, 2012)$.

Rising of middle-income class is the pre-condition for the AFN development. In the cities, the middle-income class not only enjoys the middle income in the citizens, but also share similar life style, psychological characteristics and social values (Shi et al., 2011b). Based on their economic power and reflection on the values of modern food system, they express higher interests in food consumption, such as food safety, fair trade and environment protection $(\mathrm{Fu}$ and $\mathrm{Ye}$, 2015). So, this group of people become the major initiators and participants of AFNs (Shi et al., 2011a; Shuai, 2013).

\subsection{The brief history of Alternative Food Networks in China}

Research on AFNs in China mainly started after 2005. The practices emerged much earlier than that, and have close relation with the AFN development at the global level but with clear Chinese characteristics.

At the global level, the AFNs started at the 1960s in Japan and Germany. The so- cial movements initiated by the consumers reflected the series of economic and social problems brought by the capital driven food system. The movements promoted the establishment of food certification systems which pay attention to the production, trading and consumption processes, and emphasize the value of protection of environment and producers' rights, such as organic food certification, fair trade certification (Barham, 2002). The enterprises in the mainstream food system seized this opportunity and dominate the food certification system, further leading to the conventionalization of this alternative practice and establishment of high quality food supply chain at the global level (Busch and Bain, 2004). With this background, early organic food production in China mainly sold to foreign market. It involved crossnation food companies and the producers mainly gained the organic certification from foreign certification agencies. In the record, the first export organic food was the organic tea exported from southern Zhejiang province to the Netherlands in 1990. As the largest organic certification agency in China, the Organic Food Development and Certification center certified $37429 \mathrm{mu}$, covering 105 types of products and total output reaching 20.54 tons (Sanders, 2006).

In western countries, the ecological agriculture and certification system development were promoted by the social movements. Differently, in China government plays the dominant role in ecological agricultural certification system development. Back to 1992, the Ministry of Agriculture established Green Food Development Center, in charge of the certification and man- 
agement of green agri-products. Green agriproducts allow using relatively safe chemical synthesis with quantity limitation. 1994, Department of Environment set up the Organic Food Development Centre in Nanjing, responsible for the organic agri-products' certification and management at the national level. In 2001, the Ministry of Agriculture implemented the "Hazard-free Food Action Plan" to improving the management of food safety (Scott et al., 2014). But the problems in the certification system design and operation, the food certification systems do not improve the transparency of the production processes, even lead to the consumers' doubt on the credibility and added-value of the certified food (Mol, 2014).

Entering the 21th century, the income level of urban citizens in China has been raised significantly and form a certain scale middle-income group who pursue higher values in food consumption. In existing studies, Farmers' in Guangxi Friend is an early consumer organization established by a group of young people in Liuzhou City who love rural life. They started to search local produced agri-products in 2004, and set up the "high quality local produced products exhibition room" in Liuzhou, opened the "high quality local produced products restaurant" in 2007. The ingredients of the restaurant are brought from the cooperation farmers of the organization and the ingredients are also sold at the community market. Targeting the healthy food market, Nanmazhuang Farmer Cooperative in Henan province started hazard-free rice production in 2005, and they launched the activity of buying rice and contracting lands favored by professor Wen
Tiejun and He Lihui, which turned out to be a classic case of agriculture supported by selforganized communities (Shi, 2015).Under the support of "Community Partners",a NGO in Hong Kong, Sancha and Chentang village in Heng county of Guagxi started to plant organic rice in 2005, selling the organic rice twice more expansive than the ordinary to the consumers in Hong Kong, guangzhou, Nanning and so on (Vernooy, 2012). At this stage, the practice of AFN mainly appears in the scattered form. They have jumped out of the mainstream market and the governmentleading mode, and have explored a new road, but their influence is limited.

The year of 2008 can be seen as anturning point in the development of AFN in China, because people's trust in the mainstream food system was profoundly shaken by the melamine milk scandal.The consumers further feel the urgency of looking for safe food, especially families with infants and young children (Chen et al., 2011). In the same year, School of Agricultural Economics and Rural Development, Renmin University of China in collaboration with Haidian district government in Beijing, established the Little Donkey Farm. On this basis, the national conference of CSA was held. The farm and the conference become an important push force in the widespread application of the new type of practice of food system -community-supported agriculture. Since then, a growing number of research institutions and NGOs have participated in the practice and research of AFN. In 2010, College of Humanity and Development, China Agriculture University launched "the projects of poverty alleviation of nested market". 
In 2016, Department of Sociology of Tsinghua University established the consumption and cooperation network of Famer's Friend ecological agriculture. The farmers' market for organic products, started in 2010 , is the earliest domestic farmers' market. Launched by a Japanese artist named Tadamuramegumi together with the local small organic farms, the farmer's market starts to evolve into a social enterprises under standardized operation from uncertain volunteer activities in the beginning, and combined with Shanghai Nonghao Farmers' Market and Nurture Land in Guangzhou, Farmer's Market in xi 'an starts to establish a participatory organic certification system suited to the Chinese characteristics (2015). According to the incomplete statistics from the Little Donkey far, by the end of 2015, there are about 80 community-supported agriculture farms in nearly 20 provinces and cities in the country, and traditional farmer's market are established in Beijing, Shanghai, Nanjing, Changzhou, Gguangzhou, and Chengdu and so on (Shi, 2015).

In addition to the direct activities associated with food consumption, many urban farm operated in the form of CSA have the function of offering public cultural leisure, and consumers are attracted to participate in the daily operation of the farm through their labor share. Moreover, various farming activities are held to promote the communication among consumers and consumer education is carried out to provide a natural ecological environment differing from the daily life in the city (Shao et al., 2012). At the same time, the research on nested market demonstrates that, in a broad sense, all rural tourism can replace the mainstream market pattern, which expands the business scope of the agricultural operators so as to fully tap the versatility of agriculture (Ye and Wang, 2011). From this perspective, the scale of the domestic AFN is much larger with inherent Chinese characteristics.

\subsection{Multiple actors participating in the interaction}

Based on the development course of AFN in China, the researchers reach a consensus that the AFN is both a deconstruction and a reconstruction process to the system of mainstream food, with the combination of producers and consumers as the core, and it is inseparable from the participation as well as the support from the government and different types of intermediary organizations.

\section{The Linking between Producers and Consumers}

The basic feature of the new type structure of the AFN is to reduce or even remove the intermediate links, such as middlemen, and to establish a direct link between producers and consumers. Just as professor Young Roger said, both producers and consumers in the new structure have their own particularity (van der Ploeg et al., 2012).

\subsection{The characteristics of producers in AFN}

Through the case investigation on the different AFNs in 13 provinces, Si Zhenzhong et al. (2015) have found that the "real" farmers are less involved in AFN, and a lot of the initiators and producers are urban elites who are self-proclaimed "new farmers". Tan Xuewen and Du Zhixiong (Tan and 
Du, 2015) have carried out a more detailed investigation on the characteristics of the "new farmer", and they conduct the research to the suburbs of Beijing and the surrounding 41 farms engaging in the production of AFN. Consequently, they have found that $70 \%$ of these farm operators are less than 40 years old; those who have bachelor degree or above account for $63 \%$; more than half of them are not of agricultural census register. That is to say, most of the producers who are actively engaged in alternative agriculture are young urban elites who have a deeper understanding and reflection towards the operation of the mainstream food system rather than farmers in the traditional sense. But due to their own features, they also have their own business advantage and deficiency. The advantage is that they are relatively generously funded, and according to a survey, farms with the investment of 0.1-5 million Yuan account for $78 \%$, all of which adopts he ecological agricultural technology; while the deficiency is that most of the producers don't have right to the contracted management of farm land because they have no agriculture census register so that $50 \%$ of the farms completely rely on leasing the land and $26 \%$ partly on leasing land.

But it can never be said that "real" farmers are completely excluded from the new structure, which also is not an initial intention of the development of AFN, for example, the farmers cooperated with the Farmers'Friend are traditional farmers, and the producers in the "nested market" project of China Agricultural University are the very villagers from the cooperated village, while the main problem is that it is difficult for the traditional farmers to consciously and actively participate in the construction of AFN due to the limitations of their own ability and knowledge structure.

\subsection{The characteristics of consumers in ANF}

Most of the consumers participating in the construction of ANF are middle-income urban groups. Chen Weiping et al. (2011) have investigated members of the five community-supported agriculture farms, and among these members, $65 \%$ are 31 to 40 years old, $19 \%$ are 41 to 50 years old; $86 \%$ of the respondents have a bachelor's degree; About $50 \%$ of the members' family income is more than 15000 Yuan, and the families whose income is more than 10000 Yuan accounts for $21 \%$. The above mentioned complies with the foreign case that the consumers in AFN are made up of urban elites.

But Chinese consumers has their own characteristics, and what mainly drives them to take part in AFN is to obtain safe agriproducts of high quality, but the ecological protection in the process of agricultural production and the fair trade of food are not paid much attention (Chen et al., 2011; Si et al., 2015).This has something to do with the Chinese consumers' lack of the sense of responsibility on the whole and their lack of understanding the negative externalities of their consumption behavior (Xu and Zhou, 2014).

\subsection{The interaction between producers and consumers}

The key road to tackle with the problem of asymmetrical information in the food system is to establish a direct link between 
producers and consumers so as to rebuild trust between producers and consumers and to form a good interaction between food production and consumption (Li, 2012).

The practice of AFN takes a variety of ways to establish and strengthen the interaction between producers and consumers: first, joint risk-sharing cooperation mechanism, that is, the consumers and producers undertake the potential natural and market risks together in the production, which changes the structure in which producers and consumers merely focus on individual rationality and separate from each other in the mainstream food system, and the enthusiasm of producers to participate in the production of healthy agri-food is increased (Wu, 2011); second, the open mode of production, which means consumers, the media and other third parties may get the knowledge to the production process through the on-the-spot inspectation at any time. As a result, the consumers can not only obtain the true information but also secure a naturally supervision to producers; third, increasing the frequency of interaction between producers and consumers, for example, the Gaos, a famer family, in Anlong village of Sichuan required that consumer smust carry on the field trip to the Anlong village before they order the vegetables in advance, and different types of producers will also invite consumers to take part in various activities regularly that they organize so that they can get to know the production process and experience the rural culture and life, and the interaction between consumers can simultaneously be promoted (Cheng et al., 2011; Chen, 2013b); fourth, a Shared third-party relationship, because the stud- ies done by Chen (2013b) and Shuai (2013) show that friends, relatives or acquaintances are the main reasons that encourages consumers to join AFN.

The development of modern information technology also facilitates the interaction between producers and consumers, which has become an important way to strengthen their connection. One mode is that the production and management of the whole farm are based on the modern Internet technology, for example, the e farm in Changzhou, Jiangsu province is a relative typical case, which indicates that after consumers lease the farm land, they can farm by themselves, or they can also ask the farm managers to plant for them and they can communicate with the farm managers through the network so that they can know the growing conditions of their crops at any time (Chen et al., 2012). The other mode is to use the network as a platform for the communication between producers and consumers. Many producers set up their own accounts or shops on QQ, WeChat, Weibo, Douban or Taobao, the network media which has sweeping influence so that producers can release all kinds of information about the products, the producer's ideas and the process of production, and consumers can also participate in the discussion and evaluation of the relevant information so as to establish an effective interaction between consumers and producers. The study done by Chen (2015) reveals that the interaction through the network platform has improved the consumers' sense of satisfaction with products and has enhanced the link between consumers and producers so as to improve the trust of the consumers in the 
producers.

However, no direct link between producers and consumers can completely solve the problem of the interaction and trust between them, because the characteristics of the two parties challenge the forming of their tight link: first, the inconsistency of the focus of producers and consumers causes the inner tension of the two parties' relationship. Consumers mainly concern about food security, while producers also attach great importance to the localized production and sustainable development of economy in addition to ensure safe production, so the contradiction between the supply of limited categories of agricultural products and the diversified demands of consumers is obvious (Chen et al., 2011; Yang, 2012). Second, both producers and consumers lack the ability and skills for effective communication, so the two sides can't convey their own concepts of values and needs effectively. The case study carried out by the writer shows that the farmers set the price for their ecological pork twice higher than the market price, without explaining the principles and values that drive the pricing, and because of the high price of pork of the year, twice higher than the market price, the consumers began to have doubts and discontent, but out of respect for farmers, they remained silent but chose not to continue to buy their pork, which would be a loss for both farmers and consumers (Yang et al., forthcoming). Now, the way of pricing adopted by a lot of community-supported agriculture farms is unilateral without friendly consultation with consumers. Therefore, to establish "public pool resources" the commonly recognized concept of values and norms as well as the corresponding products in AFN can't be achieved overnight, and producers and consumers are required to interact further to form a high consensus.

\subsection{Intermediary organizations participat- ing in $A F N$}

Existing research shows that different types of intermediary organizations participating in AFN contribute to setting up and stabilizing the structure of AFN, and the main types are producer organizations, consumer groups and third parties.

Producer organizations are mainly in the form of farmers' cooperatives which provide the platform for small-scale farmers so that they can be autonomous in a way and have the opportunity to participate in the decision-making process of AFN (Chen, 2014). Specifically, the cooperative offers farmers a variety of services to help farmers overcome different difficulties from production to the construction of marketing channel. Technology service help farmers make reasonable conclusion and perform the traditional way of ecological farming, or introduce new technology for organic farming; the management of production process requires that cooperative members carry out the field management in the demanded way with an eye to ensure the quality of products in the production process. The service of Market sale is to help build contact with consumers directly, organize all kinds of farming activities, and manage the sales process, etc. (Yang et al., 2014). But, as a small combination of small fathers, the cooperative is still the vulnerable side in food system, and it is difficult to fundamentally overcome the problems of insuf- 
ficient technology for small farmers, communication ability and the lack of capital.

Consumer groups are the real representation in the "community" of community-supported agriculture. Shuai (2013) indicates, in his research, that the forming and developing of the consumer group is through mobilizing members of the same concept of ecological environmental protection to participate in the groups by using the network of relationship, and the interaction among members enhances each other's relationship so as to establish a long-term trust relationship. Zeng et al. (2014) hold that besides common ideas, the infrastructure like public space and logistics and the support from the existing communities are also critical factors affecting the forming of consumer community, which is consistent with the research results in the study of the development of Italy groups of the consumer purchasing conducted by Brunori (2012). Consumers, in the form of organization, maintain contact with the producers so as to reduce the search costs of individual consumer and to keep constant and institutionalized interaction with producers and thus develop a trust relationship. At present, the development of consumer groups in our country is still relatively weak.

The third parties include various organizations like NGOs, social enterprises, scientific research institutions and so on. NGO organized the domestic training of "community-supported agriculture" for partners in Hong Kong community since 2003, and the activities of ecological agriculture project were started in 2004 in YunGuiChuan and Guangdong and Guangxi, with Heng county in Guangxi as one of the sites for the project.
SiLi ecological alternative technology center in Yunnan, an NGO engaging in environmental protection, publicized to consumers the harm caused by chemical agriculture and the advantage of ecological agriculture since 2003, and organized the purchase of organic agricultural products. Compared with NGO's support for the construction of AFN, social enterprises more directly involve themselves in the operation of the new structure, such as organic farmers' market in Beijing, Nurture Land in Guangzhou, and they become the organizers of the trading activities and middlemen of ecological agri-products, providing producers and consumers with a platform for the information exchange, and expanding the network coverage of AFN (2015). Scientific research institutions have played a key role in the construction of AFN, including the above mentioned School of Agricultural Economics and Rural Development, Renmin University of China, and College of Humanity and Development, China Agriculture University, because they are not just the introducers of new ideas, but influential actors who greatly promote the wide spread of the idea of AFN in public by organizing national network of organization and activities.

Compared with producer and consumer organizations, the third parties have advantages in knowledge store and social network, who tend to be the importer of the related concept of value and ideas of AFN, and they carry out the work of education on food security, fair trade and the like for both producers and consumers, which contributes to overcoming the problem of insufficient knowledge of values and knowing on the part of producers consumers. But because 
consumers lack the understanding of the social impact of consumer behavior, the third parties will entertain certain compromise in order to maintain the operation of the new structure, and they will publicize much more from the perspective of consumers, which, to a certain extent, weakens the shaping role of social values in the consumer's education (Klein, 2009). With the development of practice, the third parties' function is increasingly significant in the coordination and overall planning in new structure, for example, the construction of participatory security system launched by Beijing organic farmers' market is the first domestic non-commercial organic certification system, aiming at the certification of organic producers through the participation of both consumers and producers. Many domestic NGOs and social enterprises engaged in related work are united and lessons from a large amount of foreign experience are drawn to simplify the text work in the certification and reduce the cost of certification, which is a new exploration of systematized and standardized AFN.

\subsection{The support from the government}

The agricultural production and food consumption have strong external effects, which requires that the government should give priority to them in the construction of institutions and policy support. In practice, the Chinese government takes the management of food safety and the development of ecological agriculture as the important content of the policy, and rules and bodies of certification related to food safety and ecological agriculture development in our country are formulated by the ministry of agriculture and environmental protection. At the same time, the local governments are encouraging producers of agri-products to undergo the certification, for example, Shouguang in Shandong province will subsidize those cooperatives or agricultural enterprises who have obtained food certification (Yang et al., forthcoming). But the certification system is not highly recognized by the consumers in the actual operation, and there are even some consumers hold that they extremely didn't trust the certified food in the local area (Xu and $\mathrm{Wu}, 2010$ ), and the important reason is that the government establishes and operates the certification system without considering the demands and participation of consumers, and the information transparency of the operation of system is not high (Mol, 2014).

Tan and Du (2010a) also pointed out that although the government pays attention to the ecological function of agriculture, it pays less attention to the social values, like energy conservation and emissions reduction, the fair trade, and the development of small farmers in the agricultural production and food consumption, while the path of scale management and big market circulation is much more adopted. All in all, the support to and emphasis on social endogenous AFN from the government are not enough and there are two cases of the existing studies: one is the preferential policies of land and support provided by the government of Haidian district in Beijing for the little donkey farm, the other one is that Guiyang city advocats the mode of green link of "community-supported farmers" explicitly in regulations of the promotion of the construction of ecological civilization. There- 
fore, Scholars believe that the government should play a more important role in the development of AFN. Their main suggestions include: the government should undertake the consequence of soil damage, a debt to ecology caused by chemical agriculture; subsidize the producers who implement the ecological agriculture during the transitional period of production; Support smallholders' ecological agriculture and provide policy support to producers; Encourage and attract talents to participate in AFN, and promote the construction of new market channels and the popularization of ecological technology of agriculture (Cheng et al., 2011; He and Li, 2013).

\section{Conclusion}

$\mathrm{AFN}$ is a reflection on the mainstream food system, and many social actors engage in improving the condition of consumer food safety through practice, sustaining the producer's livelihood and protecting the ecological environment. AFN has developed a new trust relationship and social structure which is based on the commonly recognized values. Different concepts have their own different focus, and the communitysupported agriculture puts the emphasis on units of collective action at the micro level - the importance of "community", and it believes that the mutual assistance between urban and rural areas as well as the ecological agriculture is the path of the sustainable development of the rural community; Nested market focuses on the multiple interactions among different subjects, and it argues that products based on the common norms and common values are the core in the develop- ment of AFN; the short food supply chain focuses its attention on the development of the chain of the Chinese food supply; while the direct link between farmer and consumer analyzes the process of the food system failing to be embedded in the social structure and the process of its being re-embedded. The development of Chinese AFN is associated with the development of the system of the global mainstream and alternative food with Chinese characteristics, including the government's leading role in constructing the authentication system, the value base of consumers' participation, and the massive development of rural tourism. Intermediary organizations play an important part in introducing ideas and coordinating network; the modern information technology facilitates the interaction among different subjects. At present, the support from the government for the practice of endogenous AFN at the grassroots level is insufficient, and needs to be strengthened.

\section{References}

Elizabeth Barham (2002) Towards a theory of values-based labeling. Agriculture and Human Values 19: 349-360.

Gianluca Brunori, Adanella Rossi and Francesca Guidi (2012) On the New Social Relations around and beyond Food. Analysing Consumers' Role and Action in Gruppi di Acquisto Solidale (Solidarity Purchasing Groups). Sociologia Ruralis 52: 1-30.

Lawrence Busch and Carmen Bain (2004) New! Improved? The Transformation of the Global Agrifood System*. Rural Sociology 69: 321-346. 
Aijuan Chen (2014) China's Path in Developing Organic Agriculture: Opportunities and Implications for Small-Scale Farmers and Rural Development. Department of Geography and Environmental Management. Waterloo, Ontario, Canada: University of Waterloo.

Lili Chen, Yitao Hu, Junfeng Song, et al. (2012) Approache to Solve Food Safety Problem based on Community-Supported Agriculture Anhui Agriculture Sciences 40: 4376-4380.

Weiping Chen (2013a) Perceived value of a community supported agriculturae (CSA) working share. The construct and its dimensions. Appetite: 37-49.

Weiping Chen (2013b) The Strategies of Producers to Built Trust with Consumers under the CSA - Taking Gao's Familyin Sichuan as Example. Chinese Rural Economy: 48-60.

Weiping Chen (2015) The Built of Trust of Consumers on Producers in CSA: the Roles of Consumers' Social Media. Chinese Rural Economy: 33-46.

Weiping Chen, Jiao Huang and Mengyang Liu (2011) The Development and Further of Community-Supported Agriculture. Agricultural Outlook: 5458.

Cunwang Cheng, Huadong Zhou, Yang Shi, et al. (2011) Multiple Stakeholders' Participation, Ecological Agri-Products and Trust - the report of the "Little Donkey Farm". Lanzhou Academic Journal: 55-60.

Shanshan Du, Jianming Cai, Hua Guo, et al. (2012) Food Security-oriented Urban Agriculture Development Typologies: A Case Study of Vegetable Production in Peri-urban Beijing. Progress in Geography 31: 783-791.

Zhixiong Du and Xuewen Tan (2009) The Theory and Practice of Short Food Supply Chain. Rural Economy: 3-5.

Gail W. Feenstra (1997) Local food systems and sustainable communities. American Journal of Alternative Agriculture 12: 28-36.

Huiyang Fu and Jingzhong Ye (2015) Emerging and trapped: the Localized Development of Community-Supported Agriculture: 23-32.

David Goodman, E. Melanie DuPuis and Michael K. Goodman (2012) Alternative Food Networks: Knowledge, Practices and Politics. New York: Routledge.

Fei He and Huaiying Li (2013) Study on the Government's Responsibilities in Community-Supported Agriculture. Rural Economy: 51-54.

Xuejiao He (2007) Community-Supported Agriculture: a Sustainable Agriculture Model. Rural Economy and Technology 18: 43-45.

Jakob A. Klein (2009) Creating ethical food consumers? Promoting organic foods in urban Southwest China. Social Anthropology 17: 74-89.

Jun Li (2012) Community-Supported Agriculture Development in China and its Innovation. World Agriculture: 130132.

Jixia Lu (2016) Characteristics and Difficulties in Development of Alternative Food Networks - Taking CommunitySupported Agriculture and Nested Market as Example. Guizhou Social Sciences: 158-162. 
Terry Marsden, Jo Banks and Gillian Bristow (2000) Food supply chain approaches: Exploring their role in rural development. Sociologia Ruralis 40: 424-438.

Arthur P.J. Mol (2014) Governing China's food quality through transparency: A review. Food Control: 49-56.

Jiaen Pan and Jie Du (2012) In the View of Social Economy - Taking the Modern Rural Construction. Open Times: 5568.

Xueshu Qu and Lihui Jiao (2013) Research progress of community supported agriculture in China. Guangdong Agricultural Sciences: 214-217.

Richard Sanders (2006) A Market Road to Sustainable Agriculture? Ecological Agriculture, Green Food and Organic Agriculture in China. Development and Change 37: 201-226.

Steffanie Scott, Zhenzhong Si, Theresa Schumilas, et al. (2014) Contradictions in state- and civil society-driven developments in China's ecological agriculture sector. Food Policy 45: 158-166.

Jun Shao, Yujun Zhang, XIiong Li, et al. (2012) Study on the Recreational Mode of Community-supported Agriculturetype Urban Farms. Tourism Tribune 27: 74-79.

Xu Shen (2006) Community-Supported Agriculture - The other Market System of Sustainable Agriculture. Agricultural Environment and Development: 22-24. Yan Shi (2015) Community-Supported Agriculture in the World. The Seventh National Community-Supported Agriculture Congress. Beijing.

Yan Shi, Cunwang Cheng, Peng Lei, et al. (2011a) Safe food, green food, good food: Chinese Community Supported Agriculture and the rising middle class. International Journal of Agricultural Sustainability 9: 551-558.

Yan Shi, Cunwang Cheng, Peng Lei, et al. (2011b) Urban Eco-agriculture Development and the Rise of Middle Income Group - based on the Participatory Research of CSA of "Little Donkey Farm". Guizhou Social Sciences: 5560.

Man Shuai (2013) The Mechanism of Trust Construction on Safe Food: A Case Study of the "Food Group" in City H. Sociological Study: 183-206.

Zhenzhong Si, Theresa Schumilas and Steffanie Scott (2015) Characterizing alternative food networks in China. Agriculture \& Human Values 32: 299 313.

Zhenzhong Si and Steffanie Scott (2015) The convergence of alternative food networks within "rural development" initiatives: the case of the New Rural Reconstruction Movement in China. Local Environment: The International Journal of Justice and Sustainability: 1-18.

Xuewen Tan and Zhixiong Du (2010a) Post modern Agriculture: From an Approach of Sustainable Food Supply Chain. China Agricultural University Journal of Social Sciences Edition: 156-165.

Xuewen Tan and Zhixiong Du (2010b) Postmodern Agriculture: From an Approach of Sustainable Food Supply Chain. China Agricultural University 
Journal of Social Sciences Edition 27: 156-165.

Xuewen Tan and Zhixiong Du (2015) Short Food Supply Chain, Eco-farming and Sustainable Agricultural Development: Take the Suburbs of Beijing as an Example. Reform: 102-110.

Jan Douwe van der Ploeg, Ye Jingzhong and Sergio Schneider (2012) Rural development through the construction of new, nested, markets: comparative perspectives from China, Brazil and the European Union. Journal of Peasant Studies 39: 133-173.

Ronnie Vernooy (2012) For Food Security, China Tries an Alternative to Industrial Agriculture. Solutions 3: 62-69

David C. H. Watts, Brian Ilbery and Dam Maye (2005) Making reconnections in agro-food geography: alternative systems of food provision. Progress in Human Geography 29: 22-40.

Tiejun Wen (2007) Ecological Agriculture and Rural Environment Protection in New Rural Construction. Environment Protection: 25-27.

World Bank (2006) Enhancing agricultural innovation: how to go beyond the strengthening of research systems. Washington, D.C.: World Bank.

Qiong Wu (2011) Lillte Donkey: How the Short Supply Chain Come Back. Staple Food and Oil Market News. Zhengzhou.

Tianlong $\mathrm{Wu}$ and Tongshan Liu (2014) The Mode of Community Supported Agriculture and Its Development in China. Commecial Research: 90-94,
191.

Rongfen Xiao (2011) Analysis of Community-Supported Agriculture in the Context of Ecological Civilization. Green Science and Techonology: 7-8.

Licheng Xu and Li Zhou (2014) "Organized Irresponsibility"under Food Safety Threats -Analysis on Consumers' Behaviors and "One Family, Two Systems". China Agricultural University Journal of Social Sciences Edition 31: 124-135.

Licheng $\mathrm{Xu}$ and Li Zhou (2016) Rise of the 'Direct Farmer to Consumer Marketing' Mode and Transformation of Trust on Food Circulation: Reconstruction of'Trust Based Community'in Food System of China. Journal of Nanjing Agricultural University (Social Sciences Edition) 16: 59-70.

Licheng Xu, Li Zhou and Sumei Pan (2013) One Family, Two System: the Social Self-Protection under the Food Safety Threat. Chinese Rural Economy: 3244.

Lingling $\mathrm{Xu}$ and Linhai $\mathrm{Wu}$ (2010) Food safety and consumer willingness to pay for certified traceable food in China. Journal of the Science of Food and Agriculture 90: 1368-1373.

Bo Yang (2012) Circulation Channel Analysis of Community-supported Agricultre: Opportunities and comparision with the Mainstream Channel. Consumer Economics 28: 21-25.

Huan Yang, Laurens Klerkx and Cees Leeuwis (2014) Functions and limitations of farmer cooperatives as 
innovation intermediaries: findings Jingzhong Ye and Wen Wang (2011) The from China. Agricultural Systems 127: Emergence of Nested Market: the 115-125.

Huan Yang, Ronnie Vernooy and Cees Leeuwis (forthcoming) Farmer cooperatives and the changing agri-food system in China. China Information: A Journal on Contemporary China Studies.

Resistance of Unlimited Market and Modern Agriculture. Guizhou Social Sciences: 48-54.

Ge Yin and Zhanguo Zhu (2016) Factor Analysis of Farmers' Participation in Short Food Supply Chain. Jiangsu Agriculture Sciences 44: 501-504.

Jingzhong Ye (2015) Tales of Development: the Making and Unmaking of Illusions. Beijing: Social Sciences Academic Press (China).

Jingzhong Ye, Baoying Ding and Wen Wang (2012) An Unique Approach: Spontaneous Nested Market and Rural Development. Chinese Rural Economy: 4-12.

Cheng Zeng, Xiaoqing Cui, Yuanwen Zhong, et al. (2014) Factor Analysis of Sustainable Community in CommunitySupported Agriculture Model. China Market: 8-12.

Bo Zhao and Haiyan Ge (2014) Short Food Supply Chain: from the Viewpoint of Circulating System Governance. Study and Practice: $35-43$. 